\title{
Elections, Protest, and Alternation of Power
}

\author{
Andrew T. Little, Cornell University \\ Joshua A. Tucker, New York University \\ Tom LaGatta, Splunk Inc.
}

Canonical theories of elections assume that rules determining the winner will be followed, which necessitates separate models for democratic and nondemocratic elections. To overcome this bifurcation in the literature, we develop a model where compliance is determined endogenously. Rather than serve as a binding contract, elections are modeled solely as a public signal of the regime's popularity. However, citizens can protest against leaders who break electoral rules. Compliance is possible when the election is informative enough that citizens can coordinate on either massive protests or supporting the incumbent in the case of close results. Leaders may also step down after performing poorly in a less informative election independent of the rules, but unlike the case of rule-based alternation, this often requires citizens to protest in equilibrium. An extension shows why reports of electoral fraud are often central to post-election protests and thus why international or domestic monitoring may be required for electoral rules to be enforceable.

\section{W} hy do incumbent politicians ever cede office voluntarily? After all, most models of elections begin with the assumption that politicians are office seeking, so why do we then assume that these same actors will simply give up power when an election result indicates that they should do so? Of course, we know incumbents often do give up power after elections, as George H. W. Bush (United States, 1992), Nicholas Sarkozy (France, 2012), Slobodan Milosevič (Serbia, 2000), and Eduard Shevardnadze (Georgia, 2003) can readily attest.

However, the first two cases differ from the second two on several interrelated dimensions. First, Bush and Sarkozy stepped down following clear electoral defeat, and there was no serious doubt that they would accept this result; in contrast, Milosevič and Shevardnadze initially claimed victory. Second, Milosevič and Shevardnadze did not step down until citizens took to the streets to protest, while the turnover in the first two cases was immediate and peaceful. ${ }^{1}$ Third, these protests were in part spurred by accusations of massive electoral fraud, while the US and French elections were widely considered to be clean. Highlighting the importance of these distinctions, when Shevardnadze's successor, Mikheil Saakashvili, immediately conceded defeat for his party following Georgia's (relatively clean) 2012 parliamentary election, it was hailed as the first democratic transfer of power in the Caucasus.

In this paper, we develop a model that encompasses both patterns of turnover, which we label "democratic" (e.g., Bush, Sarkozy) and "semi-democratic" (e.g., Milosevič, Shevardnadze). Importantly, all of the distinctions highlighted above emerge in equilibrium with an extremely minimal treatment of the role of elections. More specifically, following a growing literature on nondemocratic elections, we assume that an election is nothing but a public signal of the incumbent's popularity (e.g., Cox 2009; Egorov and Sonin 2014; Gehlbach and Simpser 2015; Little 2012; Londregan and Vindigni 2006; Rozenas 2012; Svolik and Chernykh 2012).

In the model, the incumbent can step down immediately following the revelation of the election result. If she does

\footnotetext{
Andrew Little is assistant professor of government, Cornell University, Ithaca, NY 14853. Joshua Tucker is professor of politics, New York University, New York, NY 10012. Tom LaGatta is a senior data scientist at Splunk Incorporated, New York, NY 10013.

LaGatta was supported by NSF PIRE grant NSF OISE-07-30136. Data and supporting materials necessary to reproduce the numerical results in the paper are available in the JOP Dataverse (https://dataverse.harvard.edu/dataverse/jop). An online appendix with supplementary material is available at http:// dx.doi.org/10.1086/682569.

1. The protests that ousted Milosevič and Shevardnadze were relatively peaceful compared to other electoral revolutions, such as Kyrgyzstan in 2005, and even more extreme examples of post-election violence, such as the civil war in the Ivory Coast in 2010-11. Still, we use "peaceful" and "without protest" interchangeably, as our model only considers whether citizens take some kind of costly action against the regime.
}

The Journal of Politics, volume 77, number 4. Published online August 11, 2015. http://dx.doi.org/10.1086/682569 
not step down, citizens can take to the streets to protest. Following the protest, the incumbent has a second opportunity to leave office. Our predictions hinge on whether there are multiple equilibria in the "protest stage" for some election results, one where the incumbent steps down immediately and one where the incumbent does not do so. This is possible when "moderate" citizens are well informed enough about the beliefs of others to coordinate on either supporting or ousting the incumbent. Because the election generates public information about the incumbent's popularity, the model has multiple equilibria when the election is sufficiently informative. Further, moderates can use the election result as a focal point for determining whether to play an equilibrium with a high level of protest or a low level of protest.

More specifically, when the election result is highly informative, there is a class of equilibria where, when the incumbent claims victory, citizens use an aggressive protest strategy when the election result is below a critical threshold but protest less aggressively if the result is above this threshold. If this threshold corresponds to a legally codified rule (e.g., $50 \%$ of the vote) and the incumbent prefers to claim victory when citizens use the less aggressive protest strategy but prefers to step down when facing the more aggressive protest strategy, she will behave in a manner consistent with respecting the rule. As such, we say equilibria of this form resemble "rule-based" or "democratic" turnover.

When citizens cannot coordinate on multiple strategies that make it possible to keep or oust the incumbent - which happens when the election result is less informative-the incumbent may still step down following the protest (or even to preempt protest) if the election result signals that she is sufficiently weak. However, we argue that turnover in this manner should not be called democratic-even if the incumbent steps down immediately - as the critical election result that determines whether turnover occurs is a function of the exogenous parameters of the model (e.g., the cost of protest, the prior belief about the incumbent's popularity, etc.), and almost surely will not correspond to codified law. Further, it is possible that the election result below which the incumbent will choose to step down is lower than the codified election result for determining the legal "winner" of the election. If so, when the election result is higher than the threshold below which the incumbent would step down but lower than the legal threshold for declaring a winner, the appearance will be of an incumbent "ignoring" the election result and staying in power by force, as happened in Burma in 1990 and Algeria in 1991. We term turnover in this manner semi-democratic.
The second important contrast between these cases lies in the amount of protest on the equilibrium path. In the case of semi-democratic turnover, the incumbent will often claim victory and "wait things out" to see how big the protest is before stepping down, consistent with the motivating examples of Shevardnadze and Milosevič. In the case of rule-based alternation of power, however, protest tends to be minimal on the equilibrium path, as citizens either coordinate on a low level of protest or credibly threaten to protest in large enough numbers that the incumbent steps down before this happens.

Finally, we present an extension to the model that includes electoral fraud, a key component of many postelection protests (Tucker 2007). To do so, we incorporate uncertainty about how much of the election result was driven by fraud and, in addition to the election result, citizens observe a public signal of the level of fraud. This signal could correspond to media coverage or reports from international (or domestic) monitoring groups (Hyde 2012; Little 2015b). Consistent with observed behavior, our model predicts that signals indicating high levels of fraud make citizens more apt to take to the streets. The extension also provides an explanation that does not rely on moral outrage for why monitoring reports following fraudulent elections make protest more likely; instead, what is key is a shared knowledge that if the incumbent needed massive fraud to attain the observed result, then enough citizens dislike the regime to ensure that large protests will take place. Further, since better monitoring renders the election more informative, good monitoring may be required for rule-based alternation of power.

In sum, our central results are that (i) alternation of power by electoral rules or independent of electoral rules can emerge from the same model, (ii) the amount of information conveyed by the election result is a key parameter determining when compliance with electoral rules is possible, (iii) rule-based alternation tends to be more peaceful, (iv) reports of rampant electoral fraud lead to higher levels of protest, and (v) more accurate documentation of fraud can help facilitate rule-based alternation of power.

The rest of the paper is organized as follows. The first section places our argument in the context of existing work on rule of law, coordination under uncertainty, and elections as public signals. The second section presents the main model and core results on when rule-based alternation of power is possible. The third section examines when protest occurs on the equilibrium path, and the fourth section contains the extension that incorporates electoral fraud. The fifth section concludes. Proofs and other technical derivations can be found in the online appendix. 
1144 / Elections, Protest, and Alternation of Power Andrew T. Little, Joshua A. Tucker, and Tom LaGatta

\section{PAST WORK}

The possibility or realization of leaders relinquishing power following an election plays a central role in prominent theoretical and operational definitions of democracy (Cheibub, Gandhi, and Vreeland 2010; Przeworski 1991, 2015; Przeworski et al. 2000). However, most formal theories of democratization do not emphasize alternation of power but instead focus on such decisions as whether to expand the franchise (Acemoglu and Robinson 2000; Bueno de Mesquita and Smith 2009) or to hold elections (Cox 2009; Fearon 2011; Little 2012).

Two prominent explanations for compliance with electoral rules are that parties are willing to concede defeat when (i) they will have a chance to compete for power again in the future (Przeworski 1991, 2005) or (ii) citizens are able to coordinate on mass protest against leaders who fail to comply (Fearon 2011). We build on the latter by showing how uncertainty can undermine citizens' ability to coordinate on punishing those who do not step down, highlighting the informational nature of elections (and the threat posed by fraud) as a central reason that compliance with electoral rules is possible. Our model also shows how elections may cause leaders to step down as a result of the information provided by elections but not because of formal electoral rules. In doing so, we build a tighter connection between "self-enforcing" democratic elections and less democratic elections.

Our model brings together three influential lines of argument that have seen little overlap. First, we draw on the idea that laws - whether related to elections or not-can be interpreted as an equilibrium selection device in a coordination game (Basu 2000; Hardin 2003; Myerson 2013; Weingast 1997). Such coordination can explain not only why citizens follow laws but also why leaders are willing to accept limits to their power (Dragu and Polborn 2013). Further, following Schelling (1960), many have argued that anti-regime action such as protesting has a strong coordination component and that public signals (like an election result) could serve as a focal point determining whether citizens protest or not (e.g., Fearon 2011; Myerson 2013). So if post-election protest is modeled as a complete information coordination game, even an "election result" that chose a winner at random could be obeyed under the selfenforcing belief that others will support the selected candidate.

While the simplicity of this argument is appealing, the second major idea we utilize-from a literature generally falling under the umbrella term global games - is that coordination games can have a unique equilibrium when the players are uncertain about the preferences of others or about how many actors must join for a successful change to the status quo. ${ }^{2}$ In particular, a well-known result in this literature is that, across a variety of specifications, these models exhibit a unique equilibrium if the ratio of public-toprivate information about the parameter of uncertaintyin our context, the popularity of the regime - is sufficiently low (see Hellwig [2002] for the most detailed technical analysis of this relationship). Existing applied models with similar results treat the possibility of equilibrium multiplicity as either a nuisance or as purely of technical interest (Egorov and Sonin 2014; Little 2012; Morris and Shin 2000). ${ }^{3}$ We argue that, in the context of explaining compliance with electoral rules, the existence of multiple equilibria is of great substantive importance, as a lack of public information undermines citizens' ability to coordinate on supporting different leaders. If the election result does not resolve this uncertainty, then citizens may not be able to coordinate well enough to punish leaders that violate electoral rules.

The third major literature we draw on argues that elections - even in less-than-democratic settings - do generate public information about the incumbent's strength or popularity (Blaydes 2011; Cox 2009; Egorov and Sonin 2014; Gandhi and Lust-Okar 2009; Gehlbach and Simpser 2015; Little 2012; Londregan and Vindigni 2006; Magaloni 2006). ${ }^{4}$ Closest to our model, Egorov and Sonin (2014) and Little (2012) begin with the same premise, where an election is a public signal observed by a group of citizens before they decide whether to take anti-regime action. However, these models do not consider the case where the election result is informative enough that the model exhibits multiple equilibria, which is precisely what we argue is required for elec-

2. Two seminal references are Carlsson and van Damme (1993) and Morris and Shin (2003); for related applications in political science, see Bueno de Mesquita (2010), Dewan and Myatt (2008), Edmond (2013), Hollyer, Rosendorff and Vreeland (2013), Little (2012, 2015a), Rundlett and Svolik (2015), Shadmehr and Bernhardt $(2011,2013)$, and Tyson and Smith (2013).

3. An exception is Bueno de Mesquita (2014), who argues that multiplicity of equilibria in coordination games can be desirable for explaining some outcomes like the "surprise" element of revolutions.

4. This literature has primarily focused on aspects of elections we treat as exogenous, such as why elections are held (Cox 2009; Egorov and Sonin 2014; Little 2012; Magaloni 2006), the degree to which elections are manipulated (Gehlbach and Simpser 2015; Little 2015b; Rundlett and Svolik 2015; Simpser 2013), or the degree of international or domestic monitoring of elections (Hyde 2012). Models that do examine post-election protest in this framework (Kuhn 2012; Rozenas 2012; Svolik and Chernykh 2012) treat the opposition and/or citizenry as a unitary actor, abstracting away from the coordination problem central to our argument. 
toral rules to be enforceable. ${ }^{5}$ Further, these models do not treat the incumbent's decision to step down as a strategic choice, so there is minimal overlap with our main conclusions.

In a sense, our approach turns the initial impetus of the global games literature on its head. Rather than treating multiplicity of equilibria as a "straitjacket" (Morris and Shin 2003,58 ) to be escaped by introducing incomplete information, we leverage the well-known fact that introducing more public information can bring back equilibrium multiplicity to draw a link between the informationgenerating properties of elections and when electoral rules can be enforceable. The global games approach is particularly valuable for studying electoral rules, as it allows the uniqueness or multiplicity of equilibrium to be an outcome tied directly to the theoretically important variable of how informative the election is.

\section{THE MODEL}

The actors in the model are an incumbent denoted $I$ (pronoun "she") and a continuum of citizens of mass 1 (pronoun "he"), indexed by $j .{ }^{6}$ We assume whether citizens want to protest or not depends in part on how much they like or dislike the current government, which (following Bueno de Mesquita 2010) is modeled by giving each citizen a "regime sentiment" $\theta_{j}$. We write individual regime sentiments as $\theta_{j}=$ $\omega+\nu_{j}$, where $\omega$ is the average assessment of the leaderanalogous to an approval rating in a public opinion polland $\nu_{j}$ is an idiosyncratic component capturing whether or not that particular individual likes the leader more or less than average. Citizens with negative or anti-regime sentiment $\left(\theta_{j}<0\right)$ generally want to protest to force the leader to step down if necessary, while those with positive or proregime sentiment $\left(\theta_{j}>0\right)$ do not want to protest.

To capture the notion that citizens are uncertain about how much others like or dislike the regime in a tractable fashion, we assume that the citizens and the incumbent share a common prior belief over $\theta$ that is normally distributed with mean $\mu_{0}$ and precision $\tau_{0}$ (i.e., variance $1 / \tau_{0}$ ) and that the idiosyncratic terms $\left(\nu_{j}^{\prime} s\right)$ are independent and normally distributed with mean 0 and precision $\tau_{\theta}$. This prior belief could be driven by past election results, the electoral histories of parties in the political system, leaders' popularity as reported on in public opinion polls, or any

5. Others have argued that public information plays an important role in protest and other coordination games outside of the global games literature (e.g., Chwe 1998; Kuran 1989).

6. We could also think of this group of citizens as a collection of elites who have the power to oust the regime or bring other citizens (followers) out into the street. other sources of political information available to citizens (media, interpersonal relationships, etc.).

The election result $(e)$ is simply a noisy public signal of the average popularity, given by $e=\omega+\nu_{e}$. As with the other random components of the model, we assume that $\nu_{e}$ is independent from the $\nu_{j}$ 's and is normally distributed, with mean 0 and precision $\tau_{e}$. The random component $\left(\nu_{e}\right)$ accounts for any factors that might affect the election result independent of incumbent popularity, for example, uncertainty over how closely those turning out to vote resemble the population at large (or the potential protesters). In a later section, we consider the possibility that the election result is also affected by electoral fraud - which is a key source of uncertainty about how the election result reflects reality and a driving force behind post-election protestbut to keep the interpretation of our main model as simple and general as possible, we do not yet specify exactly what causes the election to be noisy. As we discuss in the conclusion, the informativeness of the election could be shaped by factors such as the quality and independence of the media, stable party systems, or electoral institutions.

After observing the election result, the incumbent has her first opportunity to step down (alternatively, "yield"), in which case the game ends. The incumbent makes this decision regardless of whether or not she "wins" the election. In fact, a major feature of the model is that we do not assume any notion of winning into the payoffs or any other aspect of the model. If the incumbent does not step down (alternatively, "stands firm" or "claims victory"), the game proceeds and citizens decide whether or not to protest. Let $a_{j}$ denote the decision to protest or not for citizen $j$, where $a_{j}=1$ means protesting and $a_{j}=0$ not protesting. Denote the proportion of protesting citizens with $\rho$. The incumbent observes the protest level and has a second opportunity to step down; if so, we say the protest succeeds. The incumbent's payoff is

$u^{\mathrm{I}}(\rho)= \begin{cases}y & \text { if stepping down before protest stage, } \\ y-\gamma \rho & \text { if stepping down after protest stage, } \\ 1-\rho & \text { if not stepping down at either opportunity. }\end{cases}$

The incumbent's payoff is a function of whether (and when) she yields and the size of the protest. She gets a partial payoff, normalized to 1 , for staying in office until the end of the game and $y \in(0,1)$ when stepping down. The incumbent pays a cost that is increasing in the protest size $\rho$, which could represent the chance that the protest movement is large enough to lead to regime change for reasons outside of the model or the cost of cracking down or making concessions to end the protest. If 
the incumbent does not step down at all, this cost is equal to the size of the protest, giving payoff $1-\rho$.

If the incumbent does step down at the second chance, the cost imposed by the protest is $\gamma \rho$ (giving total payoff $y-\gamma \rho$ ) for some $\gamma<y<1$, indicating that the cost of facing protests is mitigated by stepping down. The $\gamma<y$ restriction ensures that if enough citizens protest, the incumbent prefers stepping down at the second opportunity. For a fixed level of protest, the incumbent always gets a higher payoff from stepping down right away rather than after the protest. However, due to her uncertainty about the size of protest, she may "wait things out" and see how many citizens take to the streets before stepping down.

The citizens' utility function if the incumbent does not step down immediately after the election is similar to those in Egorov and Sonin (2014) and is a special case of the utility function in Little (2012). These payoffs depend on their regime sentiment $\left(\theta_{j}\right)$, protest decision $\left(a_{j}\right)$, and whether or not the protest succeeds:

\begin{tabular}{lcc}
\hline & Protest Fails & Protest Succeeds \\
\hline Stay home $\left(a_{j}=0\right)$ & 0 & $-b_{2} \theta_{j}$ \\
Protest $\left(a_{j}=1\right)$ & $-b_{1} \theta_{j}-c$ & $-b_{3} \theta_{j}-c$ \\
\hline
\end{tabular}

The payoff to staying home when the incumbent does not step down is normalized to 0 . If a citizen stays home during a successful protest, he gets a payoff of $-b_{2} \theta_{j}$ for some $b_{2} \geq 0$. This reflects the fact that citizens who like the regime $\left(\theta_{j}>0\right)$ will not want to see the incumbent lose power, while those who dislike the regime $\left(\theta_{j}<0\right)$ will want to see the incumbent step down even if they do not themselves protest. Citizens who protest pay a fixed cost $c>0$. Protesting against a regime that does not ultimately step down gives a payoff of $-b_{1} \theta_{j}-c$ for some $b_{1}>0$, where the first term reflects the "expressive" value of protest. That is, citizens with more intense anti-regime beliefs like protesting more (compared to staying home), even if the protest does not succeed. Finally, participating in a successful protest gives a payoff of $-b_{3} \theta_{j}-c$, where the $b_{3}>0$ term again reflects the fact that citizens who dislike the regime more get a higher benefit from joining a successful protest. ${ }^{7}$ If the

7. Some important aspects of protest that we abstract from include the role of opposition elites' strategies (Bunce and Wolchik 2011), or the possibility of learning across successive rounds of protest in a single country (Meirowitz and Tucker 2013) or cross nationally (Bunce and Wolchik 2011; Garton Ash 1999). incumbent steps down right away, the citizens get the same payoff they would if the incumbent steps down while they stay home $\left(-b_{2} \theta_{j}\right)$, though this does not affect equilibrium behavior.

It is natural to assume that $b_{3}>b_{2}$, that is, the benefit to participating (compared to staying home) for a citizen who dislikes the regime (negative $\theta_{j}$ ) is increasing in the magnitude of his distaste. Further, we assume that $b_{3}>b_{1}+b_{2}$, which implies that the relative value of protesting (compared to staying home) is increasing more in the citizen's anti-regime sentiment when the protest indeed succeeds. This is how we capture the coordination dynamics inherent to protest: as more citizens take to the streets, the incentive to join increases for those who dislike the regime.

We include the expressive payoff (i.e., the $-b_{1} \theta_{j}$ term) for a combination of substantive and technical reasons. First, it seems extreme to assume (as in some related models) that the payoff to participating in a failed protest is completely unaffected by how much a citizen dislikes the regime. Second, while some participants may believe that their actions could oust the standing government, many others (particularly in democratic countries) have no illusion that the protest will have such dramatic consequences. Given our goal of creating a unified model of post-election protest in democratic and less-than-democratic contests, we would like the fact that citizens often protest without an expectation that it will induce the incumbent to step down to arise from the model as well. On the technical end, including this term (as well as the fact that $b_{3}>b_{2}$ ) implies a useful property of "two-sided limit dominance"; that is, citizens who sufficiently dislike the regime always protest and those who sufficiently like the regime never protest.

Formally, the citizen's strategy is a mapping from the election result and his regime sentiment to the decision to protest or not. As is standard, we search for equilibria where the citizens use a symmetric strategy of the form "protest if and only if $\theta_{j}<\hat{\theta}(e)$," that is, if and only if their personal distaste for the regime is sufficiently strong, where this threshold may be a function of the realized election result. The incumbent's strategy is the set of election results for which she steps down at the first opportunity and protest sizes for which she steps down at her second opportunity. ${ }^{8}$

To recap, figure 1 shows the sequence of moves. We solve for perfect Bayesian equilibria with additional restrictions elaborated below. Relying on sequential rationality, we first determine whether the incumbent would step down

8. The incumbent could condition this decision on the election result as well, but she has full information about her payoffs at this stage. 


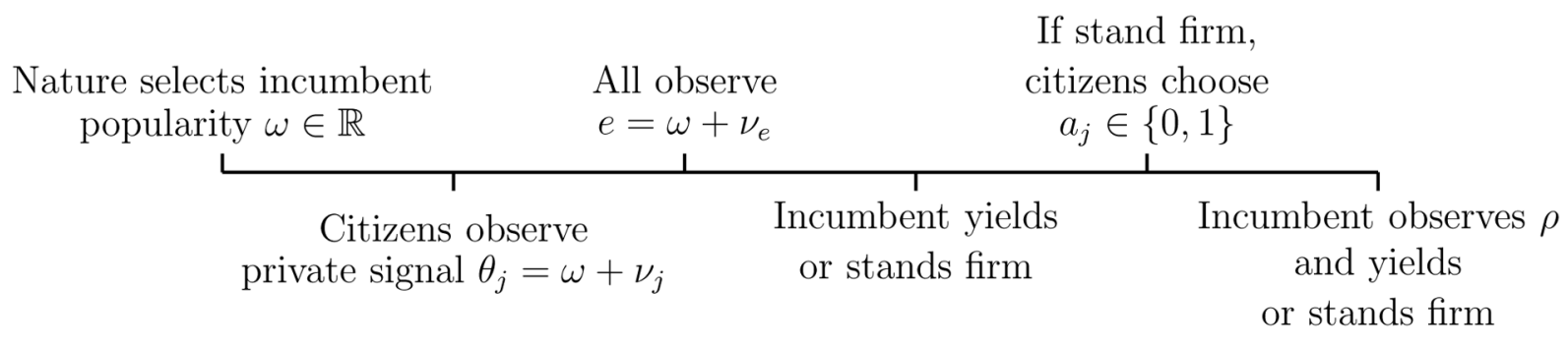

Figure 1. Timing of the model

after observing the protest size, then solve for the protest size for each election result, and finally determine when the incumbent steps down before the protest can occur.

\section{Stepping down after protest}

If the incumbent does not step down immediately and observes protest level $\rho$, she knows with certainty that she will get payoff $y-\gamma \rho$ if stepping down at the second opportunity and $1-\rho$ for standing firm. As a result, she steps down if and only if

$$
y-\gamma \rho \geq 1-\rho \Rightarrow \rho>\frac{1-y}{1-\gamma} \equiv \rho^{*} .
$$

That is, the incumbent steps down if and only if the protest level is above a critical threshold $\rho^{\star}$. As we assumed that $\gamma<$ $y<1$, this critical threshold is strictly greater than 0 and strictly less than 1 . So there are always some protest levels for which she steps down and some for which she does not. The incumbent is more apt to step down ( $\rho^{*}$ is lower) when she gets a higher payoff from stepping down (high $y$ ) and when stepping down effectively mitigates the harm of being the target of protest (low $\gamma$ ).

\section{The protest stage}

When deciding whether to take to the streets, each citizen is uncertain about the actions of others and hence uncertain whether the protest will be large enough to succeed. If a citizen assigns probability $q(\cdot)$ to the event that the protest is large enough to induce the incumbent to step down, then he will protest if and only if

$$
\begin{gathered}
q(\cdot)\left(-b_{3} \theta_{j}-c\right)+(1-q(\cdot))\left(-b_{1} \theta_{j}-c\right) \geq q(\cdot)\left(-b_{2} \theta_{j}\right), \\
\theta_{j} \leq-\frac{c}{q(\cdot)\left(b_{3}-b_{2}\right)+(1-q(\cdot)) b_{1}} .
\end{gathered}
$$

Since $\left(b_{3}-b_{2}\right)>b_{1}$ and $q(\cdot)$ is a probability and hence between 0 and 1 , the right-hand side of equation (1) is negative, increasing in $q(\cdot)$, and bounded by $\left[-c / b_{1},-c /\left(b_{3}-\right.\right.$ $\left.\left.b_{2}\right)\right]$. Let $\underline{\theta} \equiv-c / b_{1}$ and $\bar{\theta} \equiv-c /\left(b_{3}-b_{2}\right)$. So citizens who like the regime $\left(\theta_{j} \geq 0\right)$ or have only lukewarm anti-regime sentiment $\left(\bar{\theta} \leq \theta_{j} \leq 0\right)$ will never protest, and those who sufficiently dislike the regime $\left(\theta_{j}<\underline{\theta}\right)$ always protest.

For a citizen with a regime sentiment between $\underline{\theta}$ and $\bar{\theta}$, the optimal protest decision depends on his belief about the likelihood that the protest succeeds. We call these citizens moderates. The equilibrium condition for the protest stage is that when all other citizens use cutoff rule $\hat{\theta}(e)$, a moderate with a regime sentiment exactly equal to the cutoff rule-or, the marginal citizen - assigns a probability of success that makes him indifferent between protesting and not. Rearranging equation (1), write this as

$$
\begin{aligned}
q\left(\theta_{j}\right. & =\hat{\theta}(e) ; \hat{\theta}(e)) \\
& =\frac{c+b_{1} \hat{\theta}(e)}{\hat{\theta}(e)\left(b_{1}+b_{2}-b_{3}\right)} .
\end{aligned}
$$

The derivation of the probability the marginal citizen assigns to the protest succeeding (i.e., the left-hand side of eq. [2]) follows a standard calculation, which can be found in the appendix. A fixed cutoff rule for election result $e$ gives a critical regime popularity $\tilde{\omega}(e)$, such that the protest succeeds if and only if $\omega<\tilde{\omega}(e)$. By the jointly normal structure of the prior and signals, each citizen's belief about $\omega$ given $e$ and their regime sentiment is normal as well (see Greene [2008, 1014], or LaGatta [2013] for the general case). So the probability of success $q(\cdot)$ is then given by the probability that $\omega<\tilde{\omega}(e)$ for the citizen observing exactly $\theta_{j}=$ $\hat{\theta}(e)$, which gives the following equilibrium condition:

$$
\begin{gathered}
\Phi\left(\frac{\left.\hat{\theta}(e)-\frac{\tau_{0} \mu_{0}+\tau_{e} e+\left(\tau_{0}+\tau_{e}+\tau_{\theta}\right) \tau_{\theta}^{1 / 2} \Phi^{-1}\left(\rho^{*}\right)}{\tau_{0}+\tau_{e}}\right)}{\left(\tau_{0}+\tau_{e}+\tau_{\theta}\right)^{1 / 2}\left(\tau_{0}+\tau_{e}\right)^{-1}}\right) \\
=\underbrace{\frac{c+b_{1} \hat{\theta}(e)}{\hat{\theta}(e)\left(b_{1}+b_{2}-b_{3}\right)}}_{\text {Probability Protest Succeeds }},
\end{gathered}
$$


where $\Phi(\cdot)$ is the cumulative density function of a standard normal random variable. The probability that the marginal citizen attaches to the protest succeeding is continuous and increasing in the proposed equilibrium threshold $\hat{\theta}(e)$, as a higher threshold means citizens are more apt to protest. In particular, the left-hand side as a function of $\hat{\theta}(e)$ is a normal cumulative density function, so as $\hat{\theta}(e) \rightarrow-\infty$, the probability of success for the marginal citizen approaches 0 , and as $\hat{\theta}(e) \rightarrow \infty$, this probability approaches 1 .

The right-hand side of equation (3) represents the probability of the protest succeeding at which a moderate with regime sentiment $\hat{\theta}(e)$ is indifferent between protesting and not. This function is also increasing, as moderates who dislike the regime less (higher $\theta_{j}$ ) require a higher chance of success to join the protest. To intersect with the right-hand side, this function must be on $(0,1)$, and a consequence of the analysis above is that this function is strictly increasing from 0 to 1 on the interval $[\underline{\theta}, \bar{\theta}]$ and is not between 0 and 1 otherwise.

So equation (3) can only be met for $\hat{\theta}(e) \in[\underline{\theta}, \bar{\theta}]$ and must be met for at least one $\hat{\theta}(e)$ in this interval. Such an intersection is an equilibrium strategy, because the marginal citizen (i.e., a citizen observing $\theta_{j}=\hat{\theta}(e)$ ) is indifferent between protesting and not. Citizens who dislike the regime more (lower $\theta_{j}$ ) will get a higher relative payoff from protest and believe that more citizens are going to protest, thus making protest optimal. Citizens with a higher regime sentiment will get a lower relative payoff from protest and believe that the incumbent is less likely to step down, and hence they will stay home.

There is sometimes a unique threshold meeting the equilibrium condition, and sometimes there is more than one threshold. ${ }^{9}$ As discussed extensively in the literature on coordination games with uncertainty (e.g., Hellwig 2002; Morris and Shin 2003), there can be multiple equilibria when the ratio of public to private information about the parameter(s) of uncertainty is large. In our application, there are multiple equilibria when citizens have a large amount of public information about the incumbent's popularity relative to what they learn from their own regime sentiment (i.e., their private information). This is true when the election result is very informative.

A broad intuition for why this holds is that when the election result is very informative, citizens have a better idea of what others think about the regime, making it easier

9. In a slight abuse of terminology, we often use the phrases like "multiple equilibria in the protest stage" or "multiple equilibria for some election results" when it would be more precise to say that there are multiple equilibria in the model that differ in the protest strategies used by citizens for some election results. for the moderates to coordinate on different protest levels. When citizens are in a highly uncertain environment, such coordination is more difficult, resulting in a single intermediate propensity to protest.

More precisely, consider the case when the election is completely uninformative and the prior on the regime's popularity is very imprecise (i.e., $\tau_{e} \rightarrow 0$ and $\tau_{0} \rightarrow 0$ ). When this is true, citizens' only knowledge about the regime's popularity comes from their personal regime sentiment. So, the marginal citizen will always think that his regime sentiment is average, and hence the probability he assigns to the protest succeeding is fixed at some probability, $\pi \in(0,1)$. As a result, there is a unique equilibrium threshold where moderates who are willing to protest if the probability of success is greater than $\pi$ do so and other moderates will stay home.

Now consider the other extreme, where the election result is perfectly informative, meaning all citizens share the same belief about the regime's popularity and hence the distribution of other citizens' preferences regarding the incumbent is known. In this case, it is common knowledge how many citizens have a dominant strategy to protest and how many have a dominant strategy to stay home. If the number of citizens with a dominant strategy to protest is enough to force the incumbent to step down (i.e., greater than $\rho^{*}$ ), then the equilibrium is still unique as all of the moderates know the protest will succeed and hence join. If it is common knowledge that enough citizens have a dominant strategy to stay home that the protest will fail, then there is a unique equilibrium where all of the moderates stay home. However, when not enough citizens have a dominant strategy to guarantee the outcome - which will happen when the election result is intermediate-then there is an equilibrium where the moderates all join the protest and it succeeds as well as an equilibrium where the moderates all stay home and the protest fails.

The technical result that drives many of our main substantive conclusions generalizes these observations for the case where the election is informative but noisy. When the election result is not very informative, there is a unique equilibrium in the protest stage. When the election result is a very precise indicator of the regime's popularity and is not extreme enough to guarantee that the protest succeeds or fails, there are multiple equilibria; some where the moderates generally protest under the expectation that other moderates will join and some where the moderates generally stay home.

Lemma 1. (i) There exists a $\tau^{\star}>0$ such that there is a unique equilibrium in the protest stage for all election 
results if $\tau_{0}+\tau_{e}<\tau^{\star}$ (i.e., there is little public information), (ii) there is always a unique equilibrium for sufficiently low and high election results, and (iii) there exists a $\tau_{e}^{*} \geq 0$ such that if $\tau_{e} \geq \tau_{e}^{*}$, then there exists an interval $(\underline{e}, \bar{e})$ such that there are multiple equilibria for $\underline{e}<e<\bar{e}$.

All proofs can be found in the online appendix.

An advantage of the global games approach compared to a complete information coordination game is the ability to derive comparative statics on the payoffs as well as the election result:

Proposition 1. (i) When there is a unique equilibrium in the protest stage, the average size of protest and probability of the protest succeeding are decreasing in the cost of protesting against the incumbent $(c)$ and decreasing in the election result $(e)$. (ii) In the case where there are multiple equilibria for some election results, the comparative statics in i hold within the equilibria with the highest and lowest levels of protest.

Increasing the cost of protest (c) has two effects. First, from the perspective of an individual citizen, increasing the cost for a fixed expected level of protest makes participation less appealing. Second, the fact that other citizens experience the same higher cost means that they too are less likely to protest. Since the number of others taking to the streets will go down, the citizen in question becomes even more reluctant to join the protest.

The election result similarly has two effects. First, lower election results indicate that the incumbent is less popular, and, hence, even keeping the citizen strategy fixed, the expected protest level increases. Second, due to the coordination motive, citizens become more aggressive in their protest strategy when observing a lower election result as they believe others are more likely to join.

This result does not necessarily translate to the multiple equilibria case because the citizens could arbitrarily switch between different equilibria for the intermediate election results with multiplicity. Since we are concerned with when citizens can force the incumbent to step down, we restrict attention to equilibria where citizens always play the highest or lowest protest equilibrium. That is, we only consider the lowest and highest $\hat{\theta}(e)$ solving equation (3). Further, we only consider equilibria of the form "highest protest threshold for $e<e^{\star}$ and lowest protest threshold for $e<e^{\star}$ " for some $e^{\star}$ in the range of election results with multiple equi- libria. See the appendix for further discussion of this restriction and equilibrium selection in the model more generally.

\section{Stepping down before protests}

We now turn to the incumbent's decision to step down before the protest. By stepping down immediately, the incumbent is guaranteed a payoff of $y$. If claiming victory, the protest size is realized, and the incumbent steps down if and only if $\rho>\rho^{*}$. So the expected payoff for standing firm and then making the optimal decision at the second chance to step down is

$$
\begin{aligned}
u_{S F}^{I}(e) & =\underbrace{\operatorname{Pr}\left(\rho<\rho^{*} \mid e\right)\left(1-\mathbb{E}\left[\rho \mid \rho<\rho^{*}, e\right]\right)}_{\text {Payoff When Protest Fails }} \\
& +\underbrace{\operatorname{Pr}\left(\rho>\rho^{*} \mid e\right)\left(y-\gamma \mathbb{E}\left[\rho \mid \rho>\rho^{*}, e\right]\right)}_{\text {Payoff When Protest Succeeds }}
\end{aligned}
$$

If the incumbent is nearly certain that protest will be minimal, then she will not step down as her expected payoff for standing firm before the protest decision is near 1 versus a payoff of $y<1$ for stepping down. However, if the incumbent expects large protests, then she is better off stepping down right away as this guarantees a payoff of $y$, which is always better than what she will get if stepping down after protest $(y-\gamma \rho)$ or not at all $(1-\rho)$ if the protest is large.

For intermediate results, the incumbent faces a trade-off. She can guarantee a moderate payoff by stepping down right away, but she forgoes the opportunity to stay in power if the protests are in fact small. Since the expected level of protest is always decreasing in the election result, we can characterize the initial stepping down decision as follows.

Proposition 2. (i) The incumbent's payoff for standing firm prior to protest (given the citizen strategy and optimal second yielding decision) is strictly increasing in the election result, and approaches $y-\gamma$ as $e \rightarrow-\infty$ and 1 as $e \rightarrow \infty$, and (ii) the incumbent steps down if and only if the election result is sufficiently low, and this event occurs with positive probability.

Next, it is useful to define an enforceable electoral rule:

Definition. A threshold electoral rule $e_{r}$ is (i) enforceable if there is an equilibrium to the model where the incumbent steps down at the first opportunity if and only if $e<e_{r}{ }^{10}$ (ii) strongly enforceable if there

10. Equivalent results hold if we define the threshold rule as stepping down if $e \leq e_{r}$ 
exists an $\varepsilon>0$ such that any $e_{r}^{\prime} \in\left(e_{r}-\varepsilon, e_{r}+\varepsilon\right)$ is enforceable, and (iii) weakly enforceable if it is enforceable but not strongly enforceable.

That is, a rule is enforceable if there is an equilibrium where the incumbent "follows" the rule no matter what the outcome of the election. This will be possible when citizens protest enough to induce the incumbent to step down when $e<e_{r}$ and do not protest enough for the incumbent to step down when $e \geq e_{r}$. A rule is strongly enforceable if a slight change to the rule would not render it unenforceable. Approximately speaking, a rule saying the incumbent needs to get $50 \%$ of the vote to win is strongly enforceable if rules stating the incumbent needs to get $49.9 \%$ of the vote or $50.1 \%$ of the vote are also enforceable. Our main result is about when electoral rules are (strongly) enforceable.

Proposition 3. (i) If there is a unique equilibrium in the protest stage for all election results, then there is a unique weakly enforceable electoral rule and no strongly enforceable electoral rule. (ii) Let $\underline{u}_{\mathrm{SF}}^{\mathrm{I}}(e)$ and $\bar{u}_{\mathrm{SF}}^{\mathrm{I}}(e)$ be the incumbent's expected payoffs for stand-

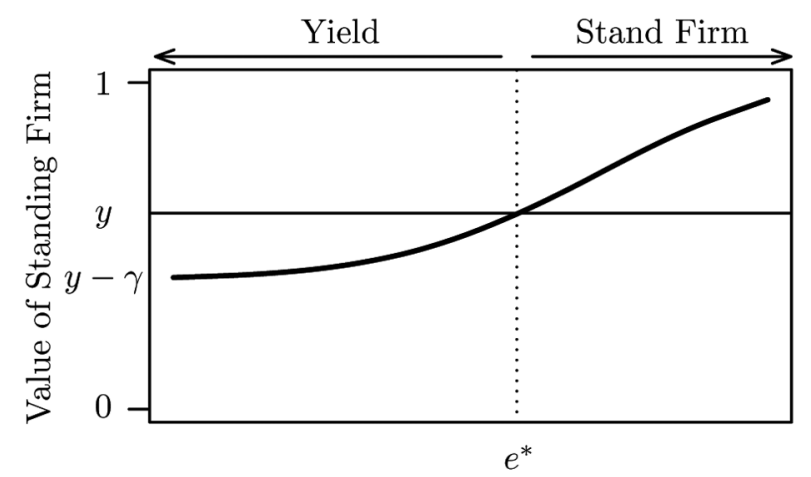

Election result $(e)$

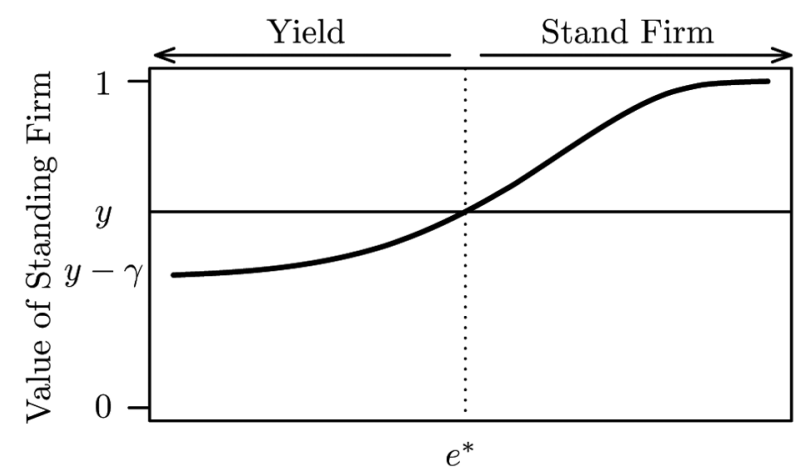

Election result $(e)$ ing firm following election result $e$ when citizens play the highest and lowest protest equilibria, respectively. If there are multiple equilibria in the protest stage for a range of election results $(\underline{\underline{e}}, \overline{\bar{e}})$ and $\underline{u}_{\mathrm{SF}}^{\mathrm{I}}(\underline{\underline{e}})<y<\bar{u}_{\mathrm{SF}}^{\mathrm{I}}(\overline{\bar{e}})$, then there exists a range of election results $(\underline{e}, \bar{e}), \underline{\underline{e}} \leq \underline{\underline{e}}<\bar{e}$ $\leq \overline{\bar{e}}$, such that any electoral rule $e_{r} \in(\underline{e}, \bar{e})$ is strongly enforceable.

Part $\mathrm{i}$ of proposition 3 states that if there is not enough public information for citizens to coordinate on different protest levels, there can never be a strongly enforceable electoral rule. Part ii states that when citizens can coordinate on multiple protest levels for some election resultsand the incumbent prefers to step down when citizens play the highest protest equilibrium at the lowest election result with multiple equilibria and prefers to stand firm when citizens play the lowest protest equilibrium after the highest election result with multiple equilibria - then there is a range of strongly enforceable electoral rules.

Figure 2 illustrates this result and its significance in terms of compliance with electoral rules. In all panels, the curve traces the expected payoff for standing firm (and

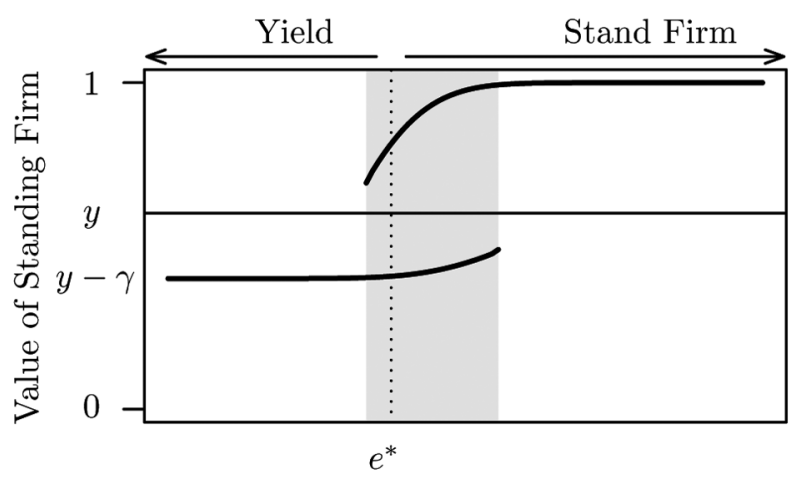

Election result $(e)$

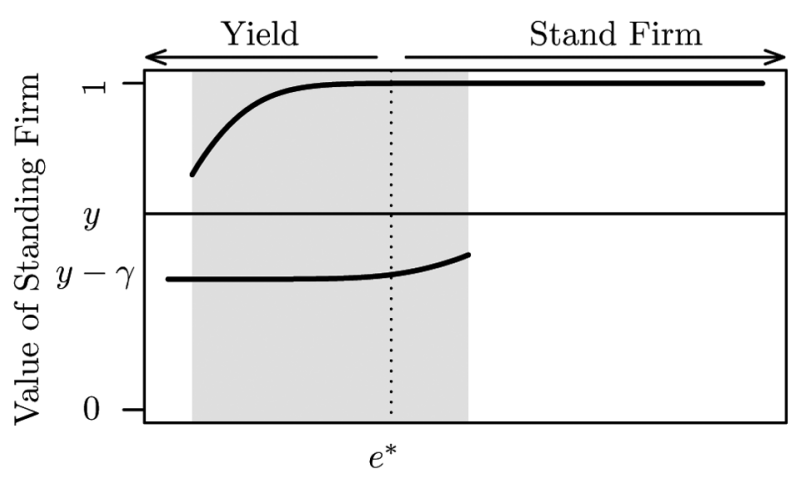

Election result $(e)$

Figure 2. Illustration of decision to step down in unique equilibrium case (left panels) and multiple equilibrium case (right panels). The bottom panels have a higher cost of protest than the top panels. 
making the optimal second yielding decision) as a function of the election result. ${ }^{11}$ The incumbent steps down immediately after the election if and only if the curve is below the value of stepping down $y$, represented by the horizontal line. The left panels show a case where the election result is noisy enough that there is always a unique equilibrium, and the right panels show a similar case where the election is more informative and hence there are multiple equilibria for intermediate election results. For both the left and right panels, there is a higher cost of conflict in the bottom panel than the top panel.

Starting with the unique equilibrium case, for both costs of conflict there is a unique $e^{\star}$ such that the incumbent steps down before protest if and only if $e<e^{\star}$. That is, $e^{\star}$ is the unique enforceable electoral rule, and because any slightly different rule would not be enforceable, $e^{\star}$ is only weakly enforceable. Moving to the bottom panel illustrates the importance of this fact: when the cost of conflict changes (even incrementally), so does the enforceable electoral rule.

This illustrates one of the central ideas of the paper: we would not consider the incumbent stepping down in the unique equilibrium case as "rule-based," because there is only one enforceable electoral rule, which changes when the cost of protest (or any other parameter of the model) changes. So the critical election result almost certainly will not correspond to a formal legal rule.

More specifically, suppose a legally codified rule states that the incumbent needs to earn $50 \%$ of the vote to win. The enforceable rule may happen to fall at a $50 \%$ vote share in a given election, but, even if so, changes in the cost of protest (or, say, the prior incumbent's popularity, which would almost surely be different in subsequent elections) will shift this critical threshold away from the legally codified rule. So some "losers" of elections will remain in office (e.g., Burma in 1990 and Algeria in 1991), while some "winners" end up stepping down, though for reasons elaborated in the following section, leaders who eventually step down despite winning the election (as in the Colored Revolutions) generally do not do so right away.

Now consider the case where the election is more informative, and hence there are multiple equilibria for some election results (right panels). In both panels, the shaded area indicates the election results for which there is a high protest equilibrium (which gives a lower payoff to standing firm) and a low protest equilibrium (higher payoff to standing firm). Where the payoff for standing firm is above

11. The $x$-axis ranges between the 5 th and 95 th percentile election results. the payoff from the high protest equilibrium but below the value of standing firm in the low protest equilibrium, whether the incumbent steps down depends on which strategy the citizens select. That is, there is a range of strongly enforceable electoral rules. Part ii of proposition 3 states that as long as the incumbent prefers to step down when citizens play the highest protest equilibrium at the lowest election result with multiple equilibria (the left edge of the shaded area) and prefers to claim victory when citizens play the lowest protest at the highest election result with multiple equilibria (the right edge of the shaded area), such a range always exists. If a legally codified rule specifying the incumbent wins if and only if their vote total lies in this range (e.g., $e<.50$ ), the written rule is strongly enforceable.

Contrasting the right panels illustrates why this is a stronger notion of enforceability. Unlike the unique equilibrium case, when the cost of protest increases (top to bottom right panel), $e^{\star}$ is still strongly enforceable, as the incumbent would step down under the high protest equilibrium but stands firm if the citizens play the low protest equilibrium for this result. So, if this corresponds to a codified rule, it is not only enforceable for the parameters in the top-right panel but for a range of scenarios. In this sense, equilibrium behavior mimics rule-based behavior without turning elections into a contract in our model. Formalizing the difference between the robustness of weakly and strongly enforceable rules to changes in the cost of protest, we have:

Proposition 4. (i) When there is a unique equilibrium in the protest stage, the enforceable electoral rule is strictly decreasing in the cost of protest. (ii) If $e_{r}$ is strongly enforceable at cost of conflict $c_{0}$, then there exists a $\delta>0$ such that $e_{r}$ is strongly enforceable for any cost of conflict $c \in\left(c_{0}-\delta, c_{0}+\delta\right)$.

Similar results hold when considering parameters other than the cost of protest.

In sum, the model has equilibria that resemble two patterns of turnover: one where the incumbent steps down if and only if she does sufficiently poorly in the election (or ensuing protests are sufficiently large) independent of electoral rules and one where electoral rules are endogenously enforced. We conclude this section with a discussion of why we believe this result and the model more generally helps bring closer the study of democratic and less-thandemocratic elections.

Compliance with electoral rules is not necessary for the most minimalist conceptions of democracy. For example, 
Przeworski (1991) famously defines elections as a system where parties lose elections - with the implication that they accept defeat-not a system where parties always accept defeat no matter how close to the margin. Still, compliance with electoral rules is clearly an important ingredient for democracy, and the fact that it is inconceivable that incumbent parties would refuse to comply in mature democracies hints that this fact likely plays an important role in how we should categorize regimes. As a result, we label turnover as it occurs in the case with a range of enforceable electoral rules "democratic." Further, if a regime that would not always comply with electoral rules holds elections that are consequential enough that ensuing protest may lead to their ouster-even if not according to constitutional procedures - it is likely safe to call the regime partially democratic. So, we label turnover in this case "semi-democratic."

Thus, while our model certainly does not capture all of the important differences between democratic and nondemocratic elections, it does endogenize a crucial aspect of democracy: compliance with rules determining who wins. Since we accomplish this with a modeling technique more closely associated with nondemocratic elections - that is, treating elections solely as a public signal of the incumbent popularity - we view this as an important bridge between the literature on these elections and standard models of democratic competition that take compliance with rules as a given, a bifurcation that is problematic in light of the large number of historical and contemporary regimes that hold elections that do not fit neatly into the democratic or autocratic bin (Levitsky and Way 2002; Miller 2013). Further, our model highlights the key theoretical variable dividing these cases: the informativeness of the election.

\section{WHEN IS PROTEST ON THE EQUILIBRIUM PATH?}

The ability to enforce electoral rules has an additional important implication tied to the informativeness of elections. Combining propositions 1 and 2 tells us that protest only occurs on the equilibrium path when the expected level is not too high: otherwise the incumbent would step down immediately. So the actual amount of protest is highest when the expected level of protest that the incumbent would face when clinging to power is intermediate.

When an election is noisy and there is a unique equilibrium in the protest stage, there are always intermediate election results where the incumbent knows she might face a large protest but stays in power anyway on the chance that the protest will turn out to be small. This is less likely to occur in the multiple equilibria case for two reasons. First, when the election result is more informative, the incumbent knows more about her popularity and what the resulting level of protest will be, and thus she can do a better job of deciding when to step down. Second, in the multiple equilibria case, the expected level of protest will tend to be very low for election results where citizens select the low protest equilibrium and very high for election results with the high protest equilibrium. This can be seen in the right panels of figure 2: the incumbent payoff for standing firm after the election result is generally very close to $y-$ $\gamma$ (meaning nearly all protest) for low election results and near 1 (meaning almost no citizens protest) for high election results.

As a result, the intermediate expected levels of protest that lead to the highest levels of protest in equilibrium are less likely in the multiple equilibria case. That is, there is little gain to waiting and seeing the actual protest size, which means that the incumbent will step down immediately after "losing" the election based on a codified rule and that she faces minimal protest (and hence almost never steps down) upon winning.

In the extreme case where the election fully reveals the incumbent's popularity, the only citizens who protest are those with a dominant strategy to do so:

Proposition 5. As $\tau_{e} \rightarrow \infty$, citizens with $\theta_{j} \in(\underline{\theta}, \bar{\theta})$ (i.e., moderates) never protest on the equilibrium path.

This highlights the second main insight of the model: in cases with turnover we label "democratic," there will be little protest on the equilibrium path, while "semi-democratic turnover" often requires citizens to actually take to the streets. An interesting contrast here is between the US and Serbian elections of 2000 , both of which were close and involved contestation of vote counting, but only the latter of which led to large-scale mass protest. Further, in the democratic case, those taking to the streets do so not because they actually expect to oust the incumbent but because they simply dislike the regime enough that the expressive component of protest outweighs its cost. This intuitively corresponds to many protests in democratic countries: all but the most extreme do not believe that their actions will lead to the president or prime minister stepping down, but they are still willing to bear the cost of protest for expressive (or other) reasons.

\section{FRAUD AND MONITORING}

Until this point, we have not explicitly considered the fact that election results can be contaminated by fraud and other types of manipulation. However, in many of our motivating examples, attempts to resolve uncertainty about how much fraud was committed played a key role in the 
post-election protests. Further, we have some idea about how citizens come to hold beliefs about how much fraud was committed: in addition to their personal experiences and the experiences of those in their social network, citizens learn from visible public reports of fraud from domestic sources, such as news media, information (such as videos) posted to the Internet, or reports of parallel vote tabulations (Herron 2010; Sjoberg 2014). They also learn (directly or indirectly) from reports issued by international observers (Hyde 2012; Little 2015b). We generically refer to these public signals as monitoring reports.

Fraud can undermine democratic turnover for two reasons. An obvious effect is that if the election result with no fraud reflects sincere voting on the part of citizens and the citizens use a majoritarian rule as a focal point determining whether the incumbent wins as above, then the incumbent can "win" an election even if she does not truly have majority support. However, we focus more here on a less obvious effect: when fraud induces uncertainty about what other citizens think about the regime, it can be harder to enforce any electoral rule. ${ }^{12}$

To take account of these considerations, let the election result be $e=\omega+x$, where $x$ represents the amount of electoral fraud. Assume $x=\bar{x}+\nu_{e}$, where $\bar{x}$ is the (common knowledge) average level of fraud and $\nu_{e}$ is a random variable reflecting whether there is more or less fraud than expected. That is, the noise of the electoral signal is now uncertainty about how much of the result was driven by fraud. While fraud is at least in part a strategic decision made by the incumbent, we treat it as exogenous here to keep the extension tractable and as multiple other recent game theoretic papers analyze fraud as a strategic choice in a similar framework (e.g., Egorov and Sonin 2014; Little 2012, 2015b; Rozenas 2012; Rundlett and Svolik 2015; Simpser 2013; Egorov and Sonin 2014).

This change alone would only be a relabeling of what the noise in the election represents, as citizens would simply subtract the average level of fraud from the election result when forming an unbiased signal of $\omega$. However, we also assume that citizens observe a monitoring report $m$, which is a noisy signal of the level of fraud. The monitoring report is normally distributed with mean $x$ and precision $\tau_{m}$. That is, $m=\bar{x}+\nu_{e}+\nu_{m}$, where $\nu_{m}$ is independent of the other noise terms and normally distributed with mean 0 and precision $\tau_{m}$. So when forming a belief about the popularity

12. Fearon (2011) makes an analogous argument about how fraud can undermine accountability in elections and how monitoring may alleviate this problem. of the incumbent, the citizens account for the monitoring report in addition to the election result and their regime sentiment.

By the jointly normal information structure, the analysis of the model with a monitoring report is nearly identical to the baseline model (see the appendix). The first main consequence of adding the monitoring report is intuitive.

Proposition 6. If there is a unique equilibrium in the protest stage or within the highest and lowest protest equilibria when there are multiple equilibria, the level of protest is increasing in the monitoring report (i.e., as the report claims more fraud), and the incumbent steps down before protest if and only if the monitoring report claims sufficiently high levels of fraud.

Just as stronger election results for the incumbent lead to less protest because they indicate that she is popular, reports of more fraud lead to more protest because they indicate that the incumbent is, for a given election result, less popular. This prediction is consistent with recent empirical work (Hyde and Marinov 2014; Rozenas 2012), which finds that public reports of fraud are associated with more post-election protest.

Further, a similar result about the relationship between the precision of the election result and the possibility of multiple equilibria holds for the precision of the monitoring report:

Proposition 7. If the monitoring report is sufficiently informative ( $\tau_{m}$ is sufficiently high), then there are multiple equilibria in the protest stage for some $e$ and $m$.

The intuition for this result is similar to that of proposition 1: one role that the monitoring report plays is to make the election result more informative, as there is less uncertainty about the level of fraud. Thus, institutions that detect electoral fraud can help consolidate democracy for a potentially unexpected reason: increasing the amount of public information and facilitating the coordination dynamics required to make electoral rules enforceable. ${ }^{13}$ Further, just as informative elections help keep protest off the

13. Hyde and Marinov (2014) and Svolik and Chernykh (2012) make a related argument that information generated by third parties like international monitors can help peaceful compliance with election results by alleviating information asymmetries between elites, not among citizens as we argue. 
equilibrium path, more informative election monitoring can serve the same purpose.

\section{CONCLUSION}

The spread of elections globally is one of the most interesting developments in comparative politics over the past half-century. Nearly every country on earth now holds elections, and in the vast majority of cases, there is at least the appearance of some competition; that is, most of these are not Soviet-style 99\% turnout and 99\% incumbent vote share elections. And yet, as a discipline, we still tend to want to dichotomize the electoral experience into "real" and "fake" elections, with the former being imbued with an almost mythical contractual power that guarantees results will be respected and the latter treated as a separate animal, if not dismissed altogether as meaningless. Somewhat surprisingly, as a field, we lack a general theory of elections. By introducing a general framework to capture how elections across regime types can facilitate alternation in power, this article is a step in that direction.

The centrality of the informational content of elections in our model and the recent literature on nondemocratic elections in general suggest that a promising direction for future research is to analyze when elections are particularly informative, which is treated as exogenous here and in most related models. To conclude, we therefore suggest three general categories of characteristics likely to affect the informativeness of elections.

The first is the general label of "free media" normally associated with liberal democracies. The most traditional aspect of free media is, of course, freedom of the press, but in the current era, we might want to also consider the extent to which access to the Internet - and particularly to social media that allow for the sharing of information about both partisan preferences and the conduct of the electionis restricted by the state. The availability of credible polling should also have an interactive effect in increasing the informativeness of the election when combined with free media of all sorts. The idea that free media is important for supporting democracy is, of course, not novel, but our model highlights a particular mechanism by which free media may support democracy that has received less attention in the extant literature. Classic treatments of liberalism as a component of democracy (e.g., Dahl 1971) tend to emphasize the importance of free media in allowing opposition candidates to be heard by the electorate prior to the election, whereas our model points to the importance of free media in providing an accurate assessment of party popularity, and in particular the incumbent's popularity, immediately after the election.
A second set of characteristics relate to the ease of translating election results to the underlying support in society for various political factions. For example, we might expect more accumulated knowledge about the support for political parties when the parties are older and the party systems in which they are embedded are more stable (Brader, Tucker and Duell 2013); similarly, we might expect the popularity of longer-serving leaders to be more fixed in the minds of citizens than those who more recently assumed office.

Finally, the informativeness of elections can be affected by characteristics of the electoral system itself. As shown in the prior section, institutions that detect and deter electoral fraud, like independent electoral commissions and international monitors, are an obvious example. Well-run electoral administrations could also serve to improve the quality of the signal from the election, perhaps by delivering that signal more quickly, in a format that is more easily accessible to more people (e.g., posting results on the Internet), or simply by increasing the confidence that citizens have that the reported result is the actual result. More broadly, much ink has been spilled on whether presidential or parliamentary systems are more susceptible to democratic collapse generally (e.g., Linz 1990) and on whether different types of electoral rules might exacerbate or mitigate conflict in society, but our model suggests a different way that these factors might have an effect on a country's democratic trajectory. For example, it may be the case that despite fostering zero-sum competition-which is assumed to be bad for democracy - presidential elections might actually make it easier for citizens to judge the relative popularity of an incumbent as compared to, for example, a complicated coalition of multiple parties.

Of course, some of these factors are endogenous to the potential for anti-regime action, and, particularly in the first category, they can affect the ability of citizens to coordinate outside of the electoral context (e.g., Little 2015a). Thus, many of the institutions we associate with democracy deserve this connection not only because they make society more liberal or elections more free but also because they generate the common knowledge required to coordinate against rule-breaking leaders.

\section{ACKNOWLEDGMENTS}

Previous versions of this paper were presented at the second annual meeting of the European Political Science Association, the Elections and Political Order conference at Emory University, and the Vanderbilt Center for the Study of Democratic Institutions/IR Colloquium. Many thanks to participants in these seminars, as well as to José Fernández 
Albertos, Val Bunce, Jennifer Gandhi, Scott Gelbach, Adam Przeworski, Alastair Smith, Milan Svolik, several anonymous reviewers, and the JOP editorial team for comments and suggestions.

\section{REFERENCES}

Acemoglu, Daron, and James A. Robinson. 2000. "Why Did the West Extend the Franchise? Democracy, Inequality, and Growth in Historical Perspective." Quarterly Journal of Economics 115 (4): 1167-99.

Basu, Kaushik. 2000. Prelude to Political Economy: A Study of the Social and Political Foundations of Economics. New York: Oxford University Press.

Blaydes, Lisa A. 2011. Elections and Distributive Politics in Mubarak's Egypt. New York: Cambridge University Press.

Brader, Ted, Joshua Tucker, and Dominick Duell. 2013. "Which Parties Can Lead Opinion? Experimental Evidence on Partisan Cue Taking in Multiparty Democracies." Comparative Political Studies 46 (11): 14851517.

Bueno de Mesquita, Bruce, and Alastair Smith. 2009. "Political Survival and Endogenous Institutional Change." Comparative Political Studies 42 (2): 167-97.

Bueno de Mesquita, Ethan. 2010. "Regime Change and Revolutionary Entrepreneurs." American Political Science Review 104 (3): 446-66.

Bueno de Mesquita, Ethan. 2014. "Regime Change and Equilibrium Multiplicity.” Unpublished manuscript, Harris School, University of Chicago.

Bunce, Valerie J., and Sharon L. Wolchik. 2011. Defeating Authoritarian Leaders in Postcommunist Countries. Cambridge: Cambridge University Press.

Carlsson, Hans, and Eric van Damme. 1993. "Global Games and Equilibrium Selection." Econometrica 61 (5): 989-1018.

Cheibub, José Antonio, Jennifer Gandhi, and James Raymond Vreeland. 2010. "Democracy and Dictatorship Revisited." Public Choice 143 (1-2): 67-101.

Chwe, Michael. 1998. "Culture, Circles, and Commercials: Publicity, Common Knowledge, and Social Coordination." Rationality and Society 10 (1): 47-75.

Cox, Gary W. 2009. "Authoritarian Elections and Leadership Succession, 1975-2004.” Unpublished manuscript, Stanford University.

Dahl, Robert. 1971. Polyarchy: Participation and Opposition. New Haven, CT: Yale University Press.

Dewan, Torun, and David P. Myatt. 2008. "The Qualities of Leadership: Direction, Communication, Obfuscation." American Political Science Review 102 (3): 351-68.

Dragu, Tiberiu, and Mattias Polborn. 2013. "The Administrative Foundation of the Rule of Law." Journal of Politics 75 (4): 1038-50.

Edmond, Chris. 2013. "Information Manipulation, Coordination, and Regime Change." Review of Economic Studies 80 (4): 1422-58.

Egorov, Georgy, and Konstantin Sonin. 2014. NBER Working Paper no. 201519, National Bureau of Economic Research, Cambridge, MA.

Fearon, James. 2011. "Self-Enforcing Democracy." Quarterly Journal of Economics 126 (4): 1661-1708.

Gandhi, Jennifer, and Ellen Lust-Okar. 2009. "Elections under Authoritarianism." Annual Review of Political Science 12:403-22.

Garton Ash, Timothy. 1999. The Magic Lantern: The Revolution of '89 Witnessed in Warsaw, Budapest, Berlin, and Prague. New York: Random House.

Gehlbach, Scott, and Alberto Simpser. 2015. "Electoral Manipulation as Bureaucratic Control." American Journal of Political Science 59 (1): $212-24$.
Greene, William H. 2008. Econometric Analysis. 6th ed. Upper Saddle River, NJ: Prentice Hall.

Hardin, Russell. 2003. Liberalism, Constitutionalism, and Democracy. New York: Oxford University Press.

Hellwig, Christian. 2002. "Public Information, Private Information, and the Multiplicity of Equilibria in Coordination Games." Journal of Economic Theory 107 (2): 191-222.

Herron, Erik S. 2010. "The Effect of Passive Observation Methods on Azerbaijan's 2008 Presidential Election and 2009 Referendum." Electoral Studies 29:417-24.

Hollyer, James R., B. Peter Rosendorff, and James Raymond Vreeland. 2013. "Transparency, Protest and Political (In)Stability." Presented at the annual meeting of the Midwest Political Science Association, Chicago.

Hyde, Susan D. 2012. The Pseudo-Democrat's Dilemma: Why Election Observation Became an International Norm. Ithaca, NY: Cornell University Press.

Hyde, Susan D., and Nikolay Marinov. 2014. "Information and SelfEnforcing Democracy: The Role of International Election Observation." International Organization 68 (2): 329-59.

Kuhn, Patrick M. 2012. "To Protest or Not: The Election Losers' Dilemma." Unpublished manuscript, University of Rochester.

Kuran, Timur. 1989. "Sparks and Prairie Fires: A Theory of Unanticipated Political Revolution.” Public Choice 61 (1): 41-74.

LaGatta, Tom. 2013. "Continuous Disintegrations of Gaussian Processes." Theory of Probability and Its Applications 57 (1): 151-62.

Levitsky, Steven, and Lucan Way. 2002. "The Rise of Competitive Authoritarianism." Journal of Democracy 13 (2): 51-65.

Linz, Juan J. 1990. “The Perils of Presidentialism." Journal of Democracy 1 (1): 51-69.

Little, Andrew T. 2012. "Elections, Fraud, and Election Monitoring in the Shadow of Revolution." Quarterly Journal of Political Science 7 (3): 249-83.

Little, Andrew T. 2015a. "Communication Technology and Protest." Presented at the annual meeting for the International Studies Association, New Orleans.

Little, Andrew T. 2015b. "Fraud and Monitoring in Noncompetitive Elections." Political Science Research and Methods 3 (1): 21-41.

Londregan, John, and Andrea Vindigni. 2006. "Voting as a Credible Threat." Unpublished manuscript, Department of Politics, Princeton University.

Magaloni, Beatriz. 2006. Voting for Autocracy: Hegemonic Party Survival and Its Demise in Mexico. New York: Cambridge University Press.

Meirowitz, Adam, and Joshua A. Tucker. 2013. "People Power or a One Shot Deal? A Dynamic Model of Protest." American Journal of Political Science 57 (2): 478-90.

Miller, Michael K. 2013. "Democratic Pieces: Autocratic Elections and Democratic Development since 1815.” British Journal of Political Science. Published online December 19. Available on CJO2013. doi:10.1017/ S0007123413000446

Morris, Stephen, and Hyun Song Shin. 2000. "Rethinking Multiple Equilibria in Macroeconomic Modeling." NBER Macroeconomics Annual 15:139-61.

Morris, Stephen, and Hyun Song Shin. 2003. "Global Games: Theory and Applications." In Mathias Dewatripont, Lars Peter Handen, and Stephen J. Turnovsky, eds., Advances in Economics and Econometrics: Theory and Applications, Eighth World Congress. Cambridge: Cambridge University Press, 56-114.

Myerson, Roger B. 2013. "Fundamentals of Social Choice Theory." Quarterly Journal of Political Science 8:305-37.

Przeworski, Adam. 1991. Democracy and the Market. New York: Cambridge University Press.

Przeworski, Adam. 2005. "Democracy as an Equilibrium." Public Choice 123 (3-4): 253-73. 
1156 / Elections, Protest, and Alternation of Power Andrew T. Little, Joshua A. Tucker, and Tom LaGatta

Przeworski, Adam. 2015. "Acquiring the Habit of Changing Governments through Elections.” Comparative Political Studies 48 (1): 101-29.

Przeworski, Adam, Michael E. Alvarez, Jose Antonio Cheibub, and Fernando Limongi. 2000. Democracy and Development: Political Institutions and Well-Being in the World, 1950-1990. New York: Cambridge University Press.

Rozenas, Arturas. 2012. “The Calculus of Dissent: Rigged Elections, Information, and Post-Election Stability." Unpublished manuscript.

Rundlett, Ashlea, and Milan W. Svolik. 2015. "Deliver the Vote! Micromotives and Macrobehavior in Electoral Fraud." Unpublished manuscript, University of Illinois at Urbana-Champaign.

Schelling, Thomas C. 1960. The Strategy of Conflict. Cambridge, MA: Harvard University Press.

Shadmehr, Mehdi, and Dan Bernhardt. 2011. "Collective Action with Uncertain Payoffs: Coordination, Public Signals and Punishment Dilemmas." American Political Science Review 105:829-51.

Shadmehr, Mehdi, and Dan Bernhardt. 2013. "State Censorship." American Economic Journal: Microeconomics 7 (2): 280-307.
Simpser, Alberto. 2013. Why Governments and Parties Manipulate Elections: Theory, Practice, and Implications. New York: Cambridge University Press.

Sjoberg, Fredrik M. 2014. "Autocratic Adaptation: The Strategic Use of Transparency and the Persistence of Election Fraud." Electoral Studies 33:233-45.

Svolik, Milan, and Svitlana Chernykh. 2012. "When Are Election Outcomes Self-Enforcing? How Third-Party Institutions Shape Incentives for Electoral Manipulation and Post-Election Protest." Unpublished manuscript.

Tucker, Joshua A. 2007. "Enough! Electoral Fraud, Collective Action Problems, and Post-Communist Colored Revolutions." Perspectives on Politics 5 (3): 535-51.

Tyson, Scott, and Alastair Smith. 2013. "Regime Insiders and Revolutions." Paper presented at the annual meeting of the Midwest Political Science Association, Chicago.

Weingast, Barry. 1997. "The Political Foundation of Democracy and the Rule of Law.” American Political Science Review 91 (2): 245-63. 